\title{
Lithium Migration Pathways and van der Waals Effects in the $\mathrm{LiFeSO}_{4} \mathrm{OH}$ Battery Material
}

\author{
Christopher Eames, ${ }^{\dagger}$ John M. Clark, ${ }^{\dagger}$ Gwenaelle Rousse, ${ }^{\ddagger}$ Jean-Marie Tarascon, ${ }^{\S}$ and M. Saiful Islam*, ${ }^{\dagger}$ \\ ${ }^{\dagger}$ Department of Chemistry, University of Bath, Bath BA2 7AY, United Kingdom \\ ${ }^{\ddagger}$ Institut de Minéralogie, de Physique des Matériaux, et de Cosmochimie (IMPMC), Sorbonne Universités-UPMC Univ Paris 06, \\ UMR CNRS 7590, Muséum National d'Histoire Naturelle, IRD UMR 206, 4 Place Jussieu, F-75005 Paris, France \\ ${ }^{\S}$ Réseau sur le Stockage Electrochimique de l'Energie (RS2E), FR CNRS 3459, Collège de France, 11 Place Marcelin Berthelot, \\ 75231 Paris Cedex 05, France
}

Supporting Information

\begin{abstract}
Layered $\mathrm{LiFeSO}_{4} \mathrm{OH}$ has recently attracted interest as a sustainable cathode material for rechargeable lithium batteries that offers favorable synthesis and processing routes. Here, the defect chemistry, lithium-ion transport pathways, and cell voltages of layered $\mathrm{LiFeSO}_{4} \mathrm{OH}$ are investigated by atomistic modeling and density functional theory (DFT) methods and compared with the tavorite polymorph. The results indicate that the layered phase exhibits two-dimensional (2D) lithium-ion diffusion with low activation energies of $\sim 0.2 \mathrm{eV}$ for long-range transport within the $b c$ plane, which is important for good rate capability. The tavorite phase also shows 2D lithium-ion diffusion but with higher activation energies of $\sim 0.7 \mathrm{eV}$. Using DFT+U techniques the experimental voltage and structural parameters are accurately reproduced for the tavorite polymorph. For the layered structure, similar accuracy in both cell voltage and structure can only be obtained if a van der Waals functional is included in the DFT methodology to account for the interlayer binding.

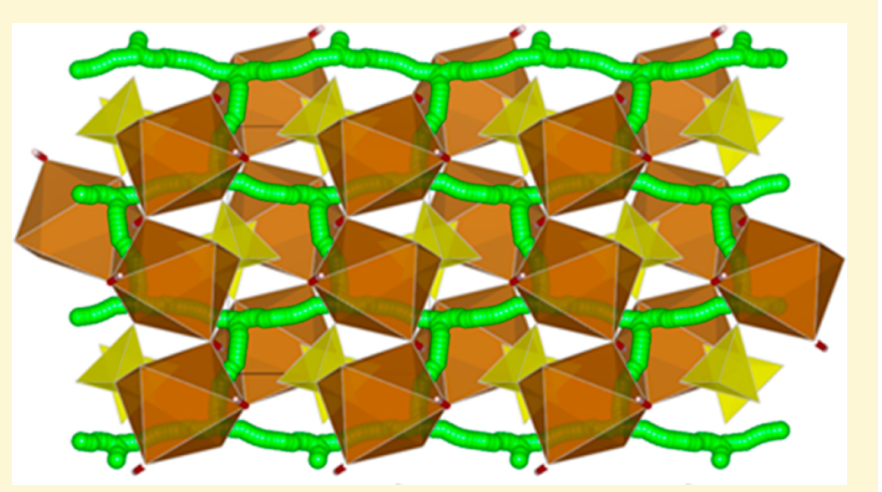

\section{INTRODUCTION}

Alternative positive electrode materials to replace the $\mathrm{LiCoO}_{2}$ system that is typically used within lithium ion batteries have attracted considerable attention. ${ }^{1-4}$ The Co-based materials pose issues associated with cost and environmental hazard, particularly for large-scale storage applications (such as hybrid or electric vehicles and back-up power systems). Hence, the field of energy storage research has been particularly active in attempting to find new cathode materials for next-generation lithium ion batteries that may provide a solution to these problems.

To date, most interest has focused on the olivine-structured orthophosphate $\mathrm{LiFePO}_{4}{ }^{1,5}$ which is already in commercial use having exhibited favorable electrochemical properties. Despite this success, attention continues to be given to finding further examples of polyanionic-based compounds containing readily abundant $\mathrm{Fe}$ to act as cathode materials in lithium batteries. In recent studies there have been changes in the polyanion, and consequently, the following materials have been proposed as alternative cathodes: $\mathrm{Li}_{2} \mathrm{FeSiO}_{4}{ }^{6,7}(160 \mathrm{mAh} / \mathrm{g}, 2.8 \mathrm{~V}$ vs $\mathrm{Li} /$ $\left.\mathrm{Li}^{+}\right) ; \mathrm{LiFeBO}_{3}{ }^{8}\left(200 \mathrm{mAh} / \mathrm{g}, 2.9 \mathrm{~V}\right.$ vs Li/ $\left.\mathrm{Li}^{+}\right) ; \mathrm{LiFeSO}_{4} \mathrm{~F}^{9-11}$ which show polymorphism with both tavorite and triplite showing redox capacities of $140 \mathrm{mAh} / \mathrm{g}$ at potentials of 3.6 and 3.9 $\mathrm{V}$ vs Li/ $\mathrm{Li}^{+}$, respectively; $\mathrm{Li}_{2} \mathrm{FePO}_{4} \mathrm{~F}^{12}(110 \mathrm{mAh} / \mathrm{g}, 3.4 \mathrm{~V}$ vs $\left.\mathrm{Li} / \mathrm{Li}^{+}\right)$; and $\mathrm{Li}_{2} \mathrm{FeP}_{2} \mathrm{O}_{7}{ }^{13}\left(110 \mathrm{mAh} / \mathrm{g}, 3.5 \mathrm{~V}\right.$ vs $\left.\mathrm{Li} / \mathrm{Li}^{+}\right)$.
Recently, it has been proposed that the newly synthesized layered iron hydroxysulfate ${ }^{14}\left(P 2_{1} / c\right)$, with composition $\mathrm{LiFeSO}_{4} \mathrm{OH}$ and related compounds may provide a new avenue for positive electrode research. Direct synthesis of $\mathrm{LiFeSO}_{4} \mathrm{OH}$ was provided by Tarascon et al. ${ }^{14}$ and results in the formation of a layered polymorph of the material. Electrochemical testing of the layered phase showed it to have a voltage of $3.6 \mathrm{~V}$ vs $\mathrm{Li} / \mathrm{Li}^{+}$for the $\mathrm{Fe}^{2+} / \mathrm{Fe}^{3+}$ redox couple with a similar discharge capacity in the range $100-110 \mathrm{mAh} / \mathrm{g}$ observed upon cycling. As with $\mathrm{LiFePO}_{4}$, the hydroxysulfate material is composed of abundant and sustainable components. Although layered $\mathrm{LiFeSO}_{4} \mathrm{OH}$ has a lower capacity than $\mathrm{LiFePO}_{4}$, it does offer other advantages, which include a slightly higher potential, a lower synthesis temperature, and a favorable processing route as neither nanomaterials nor carbon coating are needed to utilize most of its capacity. Hence, these factors make $\mathrm{LiFeSO}_{4} \mathrm{OH}$ a potential candidate for applications for which cost and abundance are essential.

In addition to the layered phase, tavorite-structured $\mathrm{FeSO}_{4} \mathrm{OH}$ has been investigated by Reddy et al. ${ }^{15}$ Recent work by Tarascon et al. ${ }^{16}$ proposed this tavorite material to

Received: March 7, 2014

Revised: May 19, 2014

Published: May 20, 2014 
crystallize in the $C 2 / c$ space group, into which $\mathrm{Li}$ could be inserted at a potential of $3.2 \mathrm{~V}$ vs $\mathrm{Li} / \mathrm{Li}^{+}$with a stable discharge capacity of $\sim 110 \mathrm{mAh} / \mathrm{g}$. The resulting lithiated composition of $\mathrm{Li}_{x} \mathrm{FeSO}_{4} \mathrm{OH}(P \overline{1}$, where $x<1)$ for this tavorite is therefore prepared by electrochemical insertion of $\mathrm{Li}$ into $\mathrm{FeSO}_{4} \mathrm{OH}$ and not by direct synthesis. Recent thermochemistry and calorimetric measurements ${ }^{17}$ find that layered $\mathrm{LiFeSO}_{4} \mathrm{OH}$ is thermodynamically more stable than the tavorite polymorph.

The present study uses well-established atomistic simulation and density functional theory (DFT) techniques to investigate key solid-state issues for both layered and tavorite $\mathrm{LiFeSO}_{4} \mathrm{OH}$ polymorphs. Atomistic simulation is well suited to treating the extensive lattice relaxation (up to several hundred ions) around charged defects and migrating ions in polar inorganic solids. DFT techniques have been applied successfully to analogous studies of other electrode materials for lithium batteries. ${ }^{18-22}$ The present work extends our recent computational studies of other polyanion-type cathodes such as $\mathrm{LiFePO}_{4}, \mathrm{Li}_{2} \mathrm{MSiO}_{4}(\mathrm{M}$ $=\mathrm{Mn}$ and $\mathrm{Fe}$ ), $\mathrm{Li}_{2} \mathrm{FeSO}_{4} \mathrm{~F}$, and $\mathrm{Li}_{2} \mathrm{FeP}_{2} \mathrm{O}_{7}{ }^{22-30}$

\section{SIMULATION METHODS}

The atomistic and DFT techniques are described in detail elsewhere, ${ }^{31,32}$ and therefore, only a general outline will be provided here. For the atomistic simulations, the interactions between ions in the hydroxysulfate polymorphs consist of a long-range Coulombic term and a short-range component representing electron-electron repulsion and van der Waals interactions. The short-range interactions were modeled using the two-body Buckingham potential, ${ }^{31}$ and an additional three-body term was used for the $\mathrm{SO}_{4}{ }^{2-}$ units as previously used for sulfates, ${ }^{3-36}$ silicates, ${ }^{26,27}$ and phosphates. ${ }^{23-25}$ The shell model $^{37}$ was used to account for polarization effects induced by charged defects. The $\mathrm{Li}-\mathrm{O}$ and $\mathrm{O}-\mathrm{O}$ interatomic potentials were taken directly from the recent study of the related tavorite $\mathrm{LiFeSO}_{4} \mathrm{~F}$, while the $\mathrm{Fe}-\mathrm{O}$ interaction was obtained by refining parameters from the same study. ${ }^{30}$ For the sulfate $\left(\mathrm{SO}_{4}\right)$ component, the interatomic potential model successfully formulated to simulate $\mathrm{M}_{2} \mathrm{SO}_{4}(\mathrm{M}=\mathrm{Na}$, $\mathrm{K}, \mathrm{Rb}$, and $\mathrm{Cs})$ and $\mathrm{XSO}_{4}(\mathrm{X}=\mathrm{Sr}, \mathrm{Ca} \text {, and } \mathrm{Ba})^{33-36}$ was used. For the hydroxyl $(\mathrm{OH})$ group, the $\mathrm{O}-\mathrm{H}$ interaction was modeled using an attractive Morse potential. This approach has recently been applied successfully to protonic defects and water incorporation in fuel cell materials. ${ }^{38-41}$ Table S1 (Supporting Information) lists the interatomic potential parameters used in this study. As argued previously, the validity of these interatomic potential methods are assessed primarily by their ability to reproduce observed crystal properties. Indeed, they are found to work well, even for compounds where there is undoubtedly a degree of covalency, such as phosphates and silicates. ${ }^{23-28,30}$

The lattice relaxation about defects (such as $\mathrm{Li}$ vacancies) and migrating ions was calculated by an implementation of the MottLittleton scheme incorporated in the GULP code. ${ }^{42}$ This method partitions the crystal lattice into two separate regions, where ions in the inner region immediately surrounding the defect $(\sim 1000$ ions $)$ are relaxed explicitly. It is worth noting that explicit relaxation of such a large number of lattice ions around defect species is not easily treated by electronic structure methods. For $\mathrm{Li}^{+}$migration calculations, energy profiles for conduction paths can be derived by calculating the energy of the migrating ion between adjacent Li sites.

DFT calculations were carried out using the plane wave code VASP. ${ }^{43}$ The basis set was converged against the stress, which is more sensitive to an under-converged basis set than the forces. A cutoff energy of $850 \mathrm{eV}$ with a $k$-point mesh density of at least $0.04 \AA^{-1}$ was needed to adequately converge the stress $(3 \times 6 \times 4$ grid $)$. PAW potentials $^{44,45}$ and the PBE functional ${ }^{46}$ were used. Our calculations employed full spin polarization, and an antiferromagnetic ordering of the moments on the $\mathrm{Fe}$ atoms was found to be lower in energy than a ferromagnetic ordering. Antiferromagnetism is common in iron sulfate-based cathode materials and has been observed in the related
$\mathrm{Li}_{2} \mathrm{Fe}\left(\mathrm{SO}_{4}\right)_{2}, \mathrm{LiFeSO}_{4} \mathrm{~F}$, and $\mathrm{NaFeSO}_{4} \mathrm{~F}$ compounds. ${ }^{11,47-49} \mathrm{DFT}+\mathrm{U}$ was used for Fe d-orbitals with an effective Hubbard $\mathrm{U}_{\text {eff }}=\mathrm{U}-J=4$ $\mathrm{eV}(J=1 \mathrm{eV})$; this value is consistent with previous work on other Febased cathodes. ${ }^{19,21,50,51}$ We should emphasize that the focus of our DFT calculations is to enhance understanding of the trends in voltage differences, which are not affected by the precise magnitude of the Hubbard U term.

Previous DFT studies on a range of oxide electrode materials ${ }^{18,22,32,52,53}$ have shown such methods to be well suited to probing lithium insertion/extraction properties and simulating precise trends in cell voltages. For both layered and tavorite polymorphs we have calculated the voltage for the $\mathrm{Fe}^{2+} / \mathrm{Fe}^{3+}$ redox couple using

$$
V=\frac{\varepsilon\left\{\mathrm{LiFeSO}_{4} \mathrm{OH}\right\}-\varepsilon\left\{\mathrm{Li}_{x} \mathrm{FeSO}_{4} \mathrm{OH}\right\}-\{1-x\} \mu\{\mathrm{Li}\}}{1-x}
$$

where $\varepsilon\{Y\}$ is the total energy of composition $Y$ and $x$ is the number of lithium atoms per formula unit removed, which in practice was one lithium atom per formula unit to produce the end member $\mathrm{FeSO}_{4} \mathrm{OH}$. Metallic lithium was used to calculate the chemical potential of a single lithium atom $\mu\{\mathrm{Li}\}$, which is standard practice for cell voltage calculations. To derive the cell voltage we have optimized the $\mathrm{LiFeSO}_{4} \mathrm{OH}$ and $\mathrm{FeSO}_{4} \mathrm{OH}$ structures and used their minimized energies in eq 1 .

To investigate structural integrity on delithiation we have performed finite temperature annealing of the structure using ab initio molecular dynamics (AIMD) in VASP with an NPT ensemble. The temperature was fixed at $50{ }^{\circ} \mathrm{C}$ for all simulations using a Langevin thermostat, and the equations of motion were controlled using the Verlet algorithm in VASP. A 0.5 fs time step was employed to accurately capture the rapid motion of the light atomic species $(\mathrm{H}$ and $\mathrm{Li})$, and each simulation was run for a total of 15 ps. A 264-atom supercell comprising $3 \times 3 \times 3$ unit cells was used, and $k$-point sampling was only necessary at the gamma point for such a large system. To reduce the computational expense we used a cutoff energy of $500 \mathrm{eV}$ and the FFT grids at a medium setting, which is standard practice in AIMD.

\section{RESULTS AND DISCUSSION}

3.1. Structures and Intrinsic Atomic Defects. The starting point of the study was to reproduce the experimentally observed crystal structures. The layered-LiFeSO ${ }_{4} \mathrm{OH}$ polymorph crystallizes in the monoclinic $\left(P 2_{1} / c\right)$ space group (Figure 1a), with edge-sharing $\mathrm{FeO}_{6}$ octahedra that form a continuous zigzag chain that runs parallel to the $b$-axis direction. These chains are connected through shared oxygen vertices to form a layered structure. On each side of the layer of $\mathrm{FeO}_{6}$ octahedra, $\mathrm{SO}_{4}$ tetrahedra are linked via oxygen vertices, hydroxyl groups form on the remaining oxygen vertices of the $\mathrm{FeO}_{6}$ octahedra that are not shared with either $\mathrm{SO}_{4}$ tetrahedra or other $\mathrm{FeO}_{6}$ octahedra. Two of the oxygen vertices of the $\mathrm{SO}_{4}$ tetrahedra are not shared with the $\mathrm{FeO}_{6}$ octahedra and point into the open channel between the layers where the lithium resides, and as such the lithium atoms are tetrahedrally coordinated.

The delithiated tavorite- $\mathrm{FeSO}_{4} \mathrm{OH}$ also crystallizes in the monoclinic space group. However, with no experimental crystal structure reported for the tavorite- $\mathrm{LiFeSO}_{4} \mathrm{OH}$ polymorph, the structure was set equivalent to that of the related tavorite$\mathrm{LiFeSO}_{4} \mathrm{~F}$ in the monoclinic $(P \overline{1})$ space group as suggested by Tarascon et al. ${ }^{14}$ who observed a structural change upon discharging the tavorite- $\mathrm{FeSO}_{4} \mathrm{OH}(\mathrm{C} 2 / \mathrm{c})$. Hence the structure of the tavorite- $\mathrm{LiFeSO}_{4} \mathrm{OH}(P \overline{1})$ polymorph (Figure $1 \mathrm{~b}$ ) is believed to include chains of alternately orientated cornersharing $\mathrm{FeO}_{4}(\mathrm{OH})_{2}$ octahedra that run parallel to the $c$-axis direction and share hydroxyl groups located on opposite oxygen vertices. The remaining oxygen vertices of the $\mathrm{FeO}_{6}$ octahedra are bonded to a sulfur atom forming $\mathrm{Fe}-\mathrm{O}-\mathrm{S}-\mathrm{O}-$ 


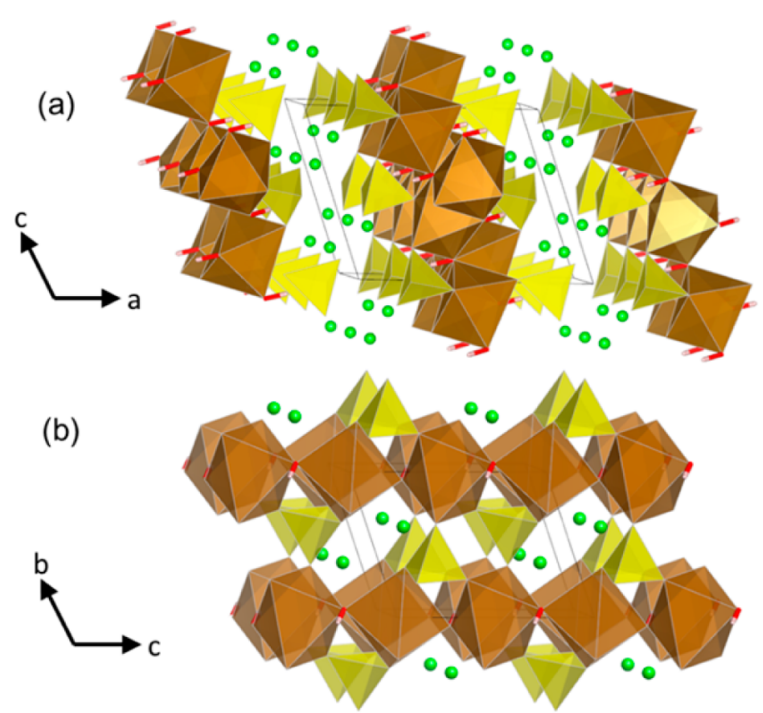

Figure 1. Crystal structures of (a) layered and (b) tavorite $\mathrm{LiFeSO}_{4} \mathrm{OH}$ polymorphs showing $\mathrm{FeO}_{6}$ octahedra (brown), $\mathrm{SO}_{4}$ tetrahedra (yellow), $\mathrm{OH}$ bonds (red with cream tip), and lithium ions (green).

Fe chains that cross-link the structure. Unlike the structure of the layered- $\mathrm{LiFeSO}_{4} \mathrm{OH}$ polymorph, all of the oxygen vertices of the $\mathrm{SO}_{4}$ tetrahedra are shared with the $\mathrm{FeO}_{6}$ octahedra.

The calculated and experimental structures for the layered polymorph are given in Table S2, Supporting Information, showing that the calculated unit cell parameters deviate from experiment by at most $0.09 \AA$, and in most cases by much less; the same is found for the $\mathrm{Li}-\mathrm{O}, \mathrm{Fe}-\mathrm{O}, \mathrm{S}-\mathrm{O}$, and $\mathrm{O}-\mathrm{H}$ bond lengths with mean deviations less than $0.06 \AA$. The accurate reproduction of the complex structure of the layered polymorph gives us confidence that the potential model can be utilized for a range of defect and migration calculations.

Atomic scale insights into the defect properties of cathode materials are crucial to gain a complete understanding of their behavior. Isolated point defect (vacancy and interstitial) energies were calculated for both layered- and tavorite$\mathrm{LiFeSO}_{4} \mathrm{OH}$, which were combined to derive the formation energies for Frenkel- and Schottky-type intrinsic defects. These defect reactions are represented by the following equations (using Kröger-Vink notation):

$$
\begin{aligned}
& \text { Li Frenkel: } \mathrm{Li}_{\mathrm{Li}}^{\times} \rightarrow V_{\mathrm{Li}}^{\prime}+\mathrm{Li}_{i}^{\bullet} \\
& \text { Fe Frenkel: } \mathrm{Fe}_{\mathrm{Fe}}^{\times} \rightarrow V_{\mathrm{Fe}}^{\prime \prime}+\mathrm{Fe}_{i}^{\bullet} \\
& \text { Schottky: } \mathrm{Li}_{\mathrm{Li}}^{\times}+\mathrm{Fe}_{\mathrm{Fe}}^{\times}+\mathrm{S}_{\mathrm{S}}^{\times}+5 \mathrm{O}_{\mathrm{O}}^{\times}+\mathrm{H}_{\mathrm{H}}^{\times} \\
& \quad \rightarrow V_{\mathrm{Li}}^{\prime}+V_{\mathrm{Fe}}^{\prime \prime}+V_{\mathrm{S}}^{\prime \prime \prime \prime \prime}+5 V_{\mathrm{O}}^{\bullet \bullet}+V_{\mathrm{O}}^{\prime}+\mathrm{LiFeSO}_{4} \mathrm{OH}
\end{aligned}
$$

As in other polyanion cathodes, the $\mathrm{Li} / \mathrm{Fe}$ "anti-site" pair defect is examined; this defect involves the exchange of $\mathrm{a} \mathrm{Li}^{+}$ ion (radius $0.74 \AA$ ) with an $\mathrm{Fe}^{2+}$ ion (radius $0.78 \AA$ ), according to

$$
\mathrm{Li}_{\mathrm{Li}}^{\times}+\mathrm{Fe}_{\mathrm{Fe}}^{\times} \rightarrow \mathrm{Li}_{\mathrm{Fe}}^{\prime}+\mathrm{Fe}_{\mathrm{Li}}^{\bullet}
$$

Such $\mathrm{Li} / \mathrm{M}$ antisite or cation exchange effects have been observed in other polyanionic-type electrode materials including olivine $\mathrm{LiMPO}_{4}(\mathrm{M}=\mathrm{Mn}, \mathrm{Fe}, \mathrm{Co}$, and

$\mathrm{Ni})^{23,24,54,55}$ and $\mathrm{Li}_{2} \mathrm{FeP}_{2} \mathrm{O}_{7}{ }^{30}$ Therefore, this type of defect is worth investigating here.

The resulting defect energies listed in Table 1 indicate two main features. First, all Frenkel and Schottky defects have

Table 1. Energies of Intrinsic Atomic Defects in Layered and Tavorite $\mathrm{LiFeSO}_{4} \mathrm{OH}$

\begin{tabular}{lccc} 
& & \multicolumn{2}{c}{ energy $(\mathrm{eV})$} \\
\cline { 3 - 4 } disorder type & equation & layered & tavorite \\
Li Frenkel & 2 & 3.55 & 2.63 \\
Fe Frenkel & 3 & 6.38 & 7.97 \\
Schottky & 4 & 20.62 & 19.46 \\
Li/Fe antisite & 5 & 2.32 & 2.99 \\
\hline
\end{tabular}

unfavorable formation energies for both $\mathrm{LiFeSO}_{4} \mathrm{OH}$ polymorphs. Second, the antisite energies are also relatively high, which suggests that there would be no significant concentration of $\mathrm{Fe}$ on $\mathrm{Li}$ sites at battery operating temperatures. This result contrasts with olivine $\mathrm{LiFePO}_{4}{ }^{23}\left(E_{\text {antisite }}=1.14 \mathrm{eV}\right)$, which exhibits antisite behavior. Therefore, these results suggest that conduction "blocking" effects involving $\mathrm{Fe}$ on $\mathrm{Li}$ sites are much less likely in the $\mathrm{LiFeSO}_{4} \mathrm{OH}$ polymorphs.

3.2. Lithium-Ion Diffusion. Li ion mobility and diffusion pathways in $\mathrm{LiFeSO}_{4} \mathrm{OH}$ are of vital importance when considering its rates of charge/discharge. However, obtaining such insight for complex polyhedral structures from experiment is far from straightforward. Atomistic modeling methods allow us to examine the energetics and possible pathways for $\mathrm{Li}^{+}$ conduction.

Figure 2 shows the different $\mathrm{Li}$ diffusion pathways considered within the layered- and tavorite- $\mathrm{LiFeSO}_{4} \mathrm{OH}$ phases. We note that other pathways were considered but were found to be excessively high in energy $(>5 \mathrm{eV})$. Energy profiles for $\mathrm{Li}$

(a)
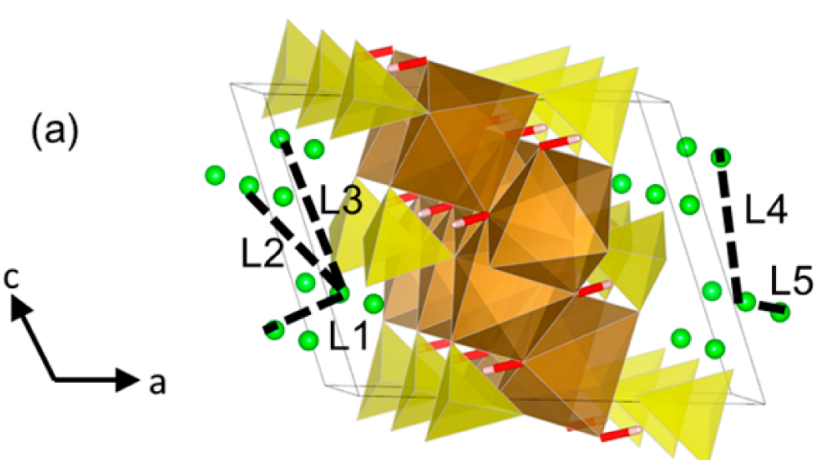

(b)
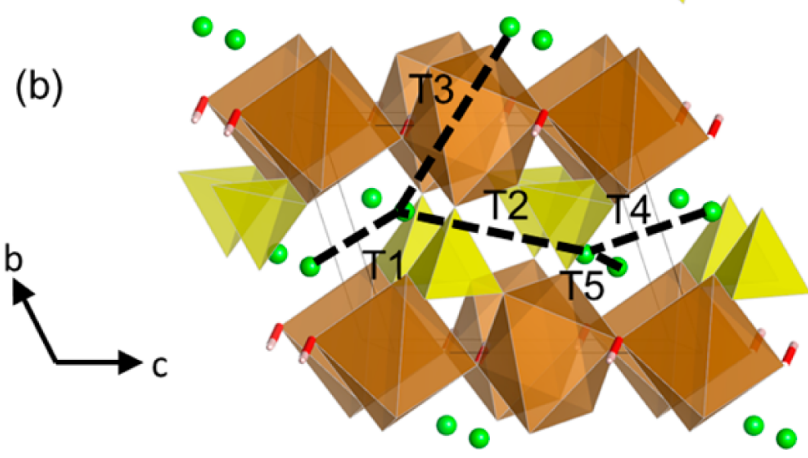

Figure 2. $\mathrm{Li}^{+}$migration pathways considered for (a) layered- and (b) tavorite- $\mathrm{LiFeSO}_{4} \mathrm{OH}$; labeled $\mathrm{L} 1-\mathrm{L} 5$ and $\mathrm{T} 1-\mathrm{T} 5$, respectively, in order of increasing $\mathrm{Li}-\mathrm{Li}$ separation. 
migration along each of these pathways can be mapped out. In this way the position of highest potential energy (i.e., the "saddle-point" configuration) can be identified from which the migration energy is derived. The resulting lowest migration energies for $\mathrm{Li}$ diffusion along each of the five pathways are reported in Table 2 .

Table 2. Energies and $\mathrm{Li}-\mathrm{Li}$ Distances for $\mathrm{Li}$ Migration in (a) Layered and (b) Tavorite $\mathrm{LiFeSO}_{4} \mathrm{OH}$ for Paths Shown in Figure 2

\begin{tabular}{ccc}
\multicolumn{3}{c}{ (a) layered $\mathrm{LiFeSO}_{4} \mathrm{OH}$} \\
\hline path & distance $(\AA)$ & $E_{\text {mig }}(\mathrm{eV})$ \\
$\mathrm{L} 1$ & 3.13 & 0.19 \\
$\mathrm{~L} 2$ & 3.49 & 0.15 \\
$\mathrm{~L} 3$ & 4.16 & 0.73 \\
$\mathrm{~L} 4$ & 5.15 & $>2.80$ \\
$\mathrm{~L} 5$ & 5.51 & $>2.80$ \\
& $(\mathrm{~b})$ tavorite $\mathrm{LiFeSO}_{4} \mathrm{OH}$ & \\
\hline path & distance $(\AA)$ & $E_{\text {mig }}(\mathrm{eV})$ \\
T1 & 3.35 & 0.38 \\
T2 & 4.75 & 0.70 \\
T3 & 4.80 & $>2.50$ \\
T4 & 4.90 & 0.72 \\
T5 & 5.18 & $>2.50$ \\
\hline
\end{tabular}

The results reveal that the L1 and L2 pathways will allow the lowest energy $\mathrm{Li}$ diffusion within the layered-phase with energy barriers of 0.19 and $0.15 \mathrm{eV}$ respectively. Such relatively low barriers suggest that the layered- $\mathrm{LiFeSO}_{4} \mathrm{OH}$ will show high $\mathrm{Li}$ mobility, which is important for good electrochemical behavior. The L1 and L2 pathways also involve the shortest $\mathrm{Li}-\mathrm{Li}$ separations (3.13 and $3.49 \AA$, respectively). Analysis of saddlepoint configurations indicate lattice relaxation of local $\mathrm{O}, \mathrm{Fe}, \mathrm{H}$, and $S$ ions of about $0.24,0.09,0.10$, and $0.15 \AA$, respectively, with the greatest displacement for adjacent $\mathrm{O}^{2-}$ ions as expected.

A higher activation energy barrier of $0.73 \mathrm{eV}$ is calculated for the $\mathrm{L} 3$ pathway, which has a longer $\mathrm{Li}-\mathrm{Li}$ separation of $4.16 \AA$. The remaining pathways (L4 and L5) are found to have high and unfavorable activation energies $(>2.80 \mathrm{eV})$ probably due to the migration distance exceeding $5 \AA$. Migration of $\mathrm{Li}$ ions from a $b c$-plane on one side of the layer of $\mathrm{FeO}_{6}$ and $\mathrm{SO}_{4}$ polyhedra to $\mathrm{Li}$ ions in the $b c$-plane on the other side would encounter separations of $\geq 8.0 \AA$ in addition to significant steric hindrance, and needless to say, these pathways are highly unfavorable.

In short, the combination of the highly favorable $\mathrm{L} 1$ and $\mathrm{L} 2$ migration pathways suggests that layered- $\mathrm{LiFeSO}_{4} \mathrm{OH}$ will facilitate long-range diffusion along both the $b$-axis and $c$-axis directions, and as such, the structure shows two-dimensional (2D) $\mathrm{Li}$ migration within the $b c$-plane. The final simulated paths for long-range $\mathrm{Li}^{+}$diffusion are shown in Figure 3.

For the tavorite-phase Table 2 reveals the T1, T2, and T4 pathways have the lowest energy barriers for $\mathrm{Li}$ diffusion of $0.38,0.70$, and $0.72 \mathrm{eV}$, respectively. These activation energy barriers for tavorite- $\mathrm{LiFeSO}_{4} \mathrm{OH}$ suggest much slower $\mathrm{Li}$ mobility as they are significantly higher than the corresponding values calculated for the layered-phase. The simulated paths for long-range $\mathrm{Li}^{+}$diffusion within tavorite- $\mathrm{LiFeSO}_{4} \mathrm{OH}$ are shown in Figure 4. The combination of the moderately favorable $\mathrm{T} 1$, $\mathrm{T} 2$, and $\mathrm{T} 4$ migration pathways suggests tavorite- $\mathrm{LiFeSO}_{4} \mathrm{OH}$ will facilitate long-range diffusion along both $a$-axis and $c$-axis

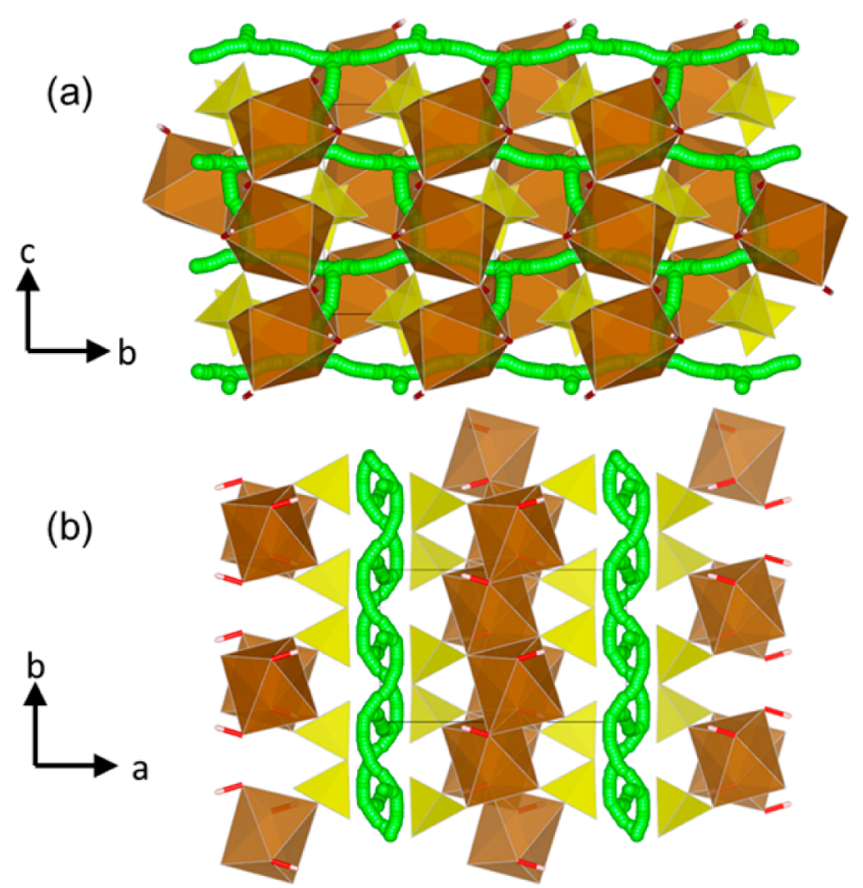

Figure 3. Calculated low energy pathways for long-range $\mathrm{Li}^{+}$migration along the $b$ - and $c$-axes directions within layered- $\mathrm{LiFeSO}_{4} \mathrm{OH}$ with activation energies of $\leq 0.19 \mathrm{eV}$; simulations indicate quasi-2D transport and nonlinear trajectories $\left(\mathrm{Li}^{+}\right.$pathways in green); (a) $a$ axis view and (b) $c$-axis view.

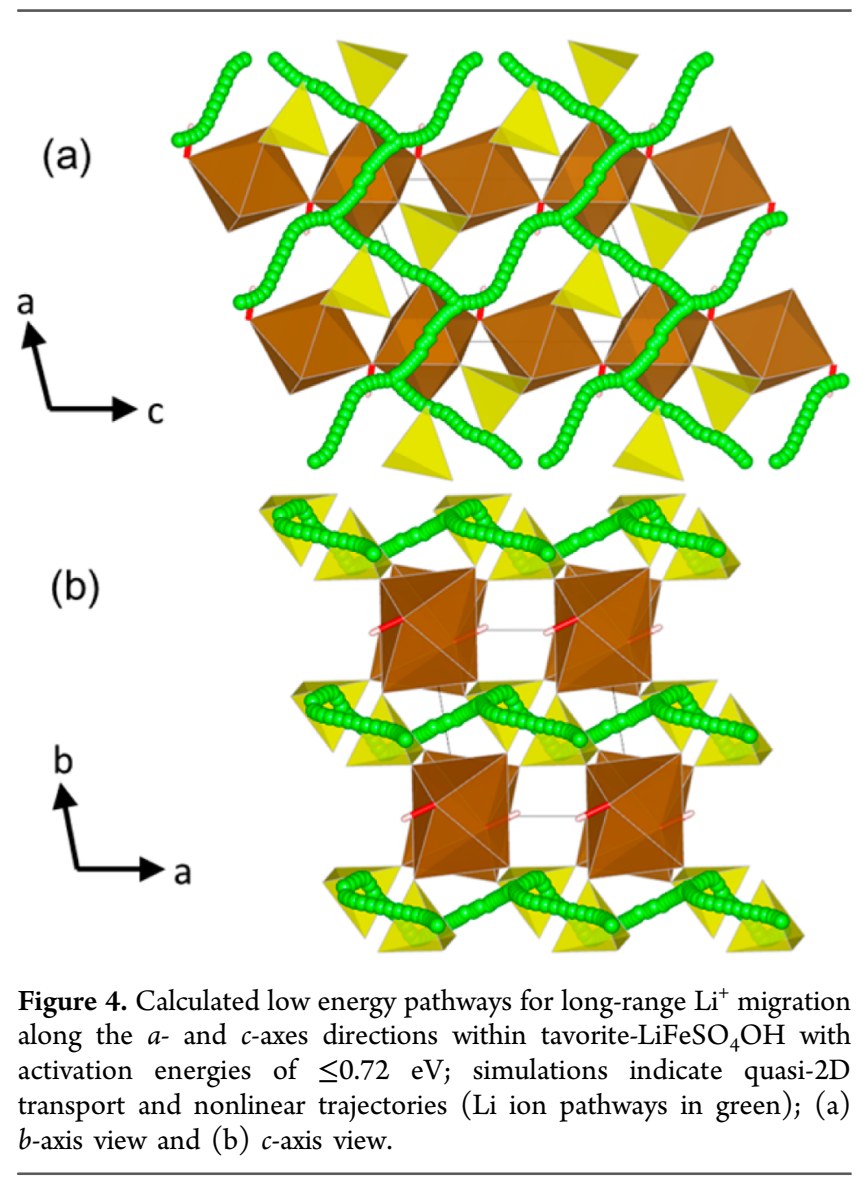

directions, and as such, the structure shows quasi-twodimensional (2D) Li migration within the ac-plane. 
Table 3. Structural Parameters of Layered $\mathrm{LiFeSO}_{4} \mathrm{OH}$ and $\mathrm{FeSO}_{4} \mathrm{OH}$ Calculated with DFT and DFT+optPBE-vdW Compared to Experimental Data ${ }^{14}$

\begin{tabular}{|c|c|c|c|c|c|}
\hline \multicolumn{6}{|c|}{ layered $\mathrm{LiFeSO}_{4} \mathrm{OH}$} \\
\hline & exptl & $\mathrm{DFT}+\mathrm{U}$ & $\Delta$ & $\mathrm{DFT}+\mathrm{U}+$ optPBE-vdW & $\Delta$ \\
\hline$a(\AA)$ & $9.5147(1)$ & 9.7470 & +0.2323 & 9.5655 & +0.0508 \\
\hline$b(\AA)$ & $5.5087(1)$ & 5.5424 & +0.0337 & 5.5099 & +0.0012 \\
\hline$c(\AA)$ & $7.3755(1)$ & 7.4956 & +0.1201 & 7.3950 & +0.0195 \\
\hline$\beta(\operatorname{deg})$ & $109.109(6)$ & 110.020 & +0.911 & 109.042 & -0.067 \\
\hline volume $\left(\AA^{3}\right)$ & $365.28(1)$ & 380.46 & +15.18 & 368.42 & +0.14 \\
\hline \multicolumn{6}{|c|}{ layered $\mathrm{FeSO}_{4} \mathrm{OH}$} \\
\hline & $\operatorname{exptl}^{a}$ & $\mathrm{DFT}+\mathrm{U}$ & $\Delta$ & $\mathrm{DFT}+\mathrm{U}+$ optPBE-vdW & $\Delta$ \\
\hline$a(\AA)$ & $9.481(3)$ & 9.7826 & +0.3016 & 9.3698 & -0.1112 \\
\hline$b(\AA)$ & $5.296(2)$ & 5.4023 & +0.1063 & 5.3258 & +0.0298 \\
\hline$c(\AA)$ & $7.207(2)$ & 7.4670 & +0.2600 & 7.3756 & +0.1686 \\
\hline$\beta(\operatorname{deg})$ & $110.55(3)$ & 111.661 & +1.111 & 112.366 & +1.816 \\
\hline volume $\left(\AA^{3}\right)$ & $338.9(2)$ & 366.76 & +27.86 & 340.37 & +1.47 \\
\hline
\end{tabular}

Our simulations reveal curved paths between adjacent Li sites for both the layered- (Figure 3) and tavorite-phases (Figure 4), which produces "wave-like" trajectories for long-range migration. It is worth noting that analogous, curved $\mathrm{Li}^{+}$migration paths were first predicted from atomistic simulation studies of $\mathrm{LiFePO}_{4},{ }^{23}$ which were subsequently confirmed by neutron diffraction maximum entropy method (MEM) analysis. ${ }^{56}$

3.3. Bulk Structures and Cell Voltages. As with the potentials-based calculations, we have also assessed various DFT-based methods in terms of the reproduction of the crystal structure and the cell voltage. Structural optimization of the asprepared layered- $\mathrm{LiFeSO}_{4} \mathrm{OH}\left(P 2_{1} / c\right)$, layered-FeSO $\mathrm{F}_{4} \mathrm{OH}$ $\left(P 2_{1} / c\right)$, and tavorite- $\mathrm{FeSO}_{4} \mathrm{OH}(\mathrm{C} 2 / \mathrm{c})$ was performed based on the crystal structures observed experimentally. ${ }^{14}$ There is no experimental crystal structure reported for the tavorite$\mathrm{LiFeSO}_{4} \mathrm{OH}$ phase, and therefore, the structure was set equivalent to that of the related tavorite- $\mathrm{LiFeSO}_{4} \mathrm{~F}$ as suggested by Tarascon et al. ${ }^{14}$ Cell voltage trends of $\mathrm{LiFeSO}_{4} \mathrm{~F}$ polymorphs have been examined previously by $\mathrm{DFT}+\mathrm{U}$ calculations combined with crystallographic and electrostatic analyses. ${ }^{29}$ Our calculated energetics indicate that the layered polymorph of $\mathrm{LiFeSO}_{4} \mathrm{OH}$ is thermodynamically more stable than tavorite, which agrees with recent calorimetry studies. ${ }^{17}$

In many layered materials such as graphite, boron nitride, and $\mathrm{V}_{2} \mathrm{O}_{5}$, dispersion interactions between the layers are known to be significant. ${ }^{57-59}$ Since standard DFT methods do not include such van der Waals (vdW) interactions explicitly we have tested two types of vdW enhanced DFT schemes: semiempirical vdW $\left({\mathrm{G} 06^{60}}^{6}\right)$ and an explicit vdW exchange correlation functional (optPBE-vdW ${ }^{61}$ ). In general, we find that the latter vdW exchange correlation functional method better reproduces the structure and voltages of the layered phase; in the remainder of this work we report results obtained in this way. In Table S3, Supporting Information, data generated using the semiempirical vdW method are listed. We note that other recent studies have shown the significance of dispersioncorrected DFT in treating ion intercalation in graphite ${ }^{62,63}$ and organic cathode materials, ${ }^{64,65}$ but there is limited work on inorganic polyanion-type cathodes.

The calculated structural parameters of layered $\mathrm{LiFeSO}_{4} \mathrm{OH}$ and $\mathrm{FeSO}_{4} \mathrm{OH}$ are presented in Table 3. It can be seen that using an explicit van der Waals functional (DFT+U+optPBE$\mathrm{vdW}$ ) provides a better agreement with the experimental structures than standard DFT+U. The improvement is mainly due to a more accurate interlayer spacing obtained by introducing dispersion interactions. The unit cell $a$ parameter, which is almost parallel to the interlayer direction, can be used to assess the difference in the interlayer spacing between experiment and calculations. For $\mathrm{LiFeSO}_{4} \mathrm{OH}$ the $\Delta a$ difference with experiment is reduced from $+2.4 \%$ with standard DFT to $+0.5 \%$ with DFT+optPBE-vdW. For $\mathrm{FeSO}_{4} \mathrm{OH}$ the $\Delta a$ difference is reduced from $+3.2 \%$ to $-1.2 \%$. We note here that the delithiated composition for the experimental structural data is $\mathrm{Li}_{0.1} \mathrm{FeSO}_{4} \mathrm{OH}$; possible extraction of a further $0.1 \mathrm{Li}$ per formula unit would decrease the interlayer spacing slightly and be closer to the calculated $\mathrm{FeSO}_{4} \mathrm{OH}$ structure.

Using the total energies of these relaxed structures an average intercalation voltage has been derived for each phase according to eq 1 , and these are listed in Table 4 . For the layered phase

Table 4. Comparison of Calculated and Experimental Cell Voltages (vs $\mathrm{Li} / \mathrm{Li}^{+}$) for Layered and Tavorite Hydroxysulfates

\begin{tabular}{lcc} 
& \multicolumn{2}{c}{ voltage $(\mathrm{V})$} \\
\cline { 2 - 3 } \multicolumn{1}{c}{ technique } & layered & tavorite \\
experiment & 3.60 & 3.20 \\
DFT+U & 4.28 & 3.40 \\
DFT+U+optPBE-vdW & 3.87 & 3.40 \\
\hline
\end{tabular}

the cell voltage computed when van der Waals effects are not included is severely overestimated by about $0.7 \mathrm{~V}$, which is unusually large for $\mathrm{DFT}+\mathrm{U}$ calculations. In contrast, the calculated voltage using optPBE-vdW is $3.87 \mathrm{~V}$ in much better agreement with the measured value of $3.6 \mathrm{~V}$. To further understand this large contribution of van der Waals interactions to the computed voltage we must return to the structural parameters.

The agreement in interlayer spacing found for both layered $\mathrm{LiFeSO}_{4} \mathrm{OH}$ and $\mathrm{FeSO}_{4} \mathrm{OH}$ compositions on inclusion of vdW effects would suggest that these interactions are important for interlayer binding. We have confirmed this by computing the binding energy versus the interlayer spacing. Such a binding potential is clearly present in the binding energy curve (Figure S1, Supporting Information) with a minimum at the observed interlayer spacing. The stronger vdW interactions in $\mathrm{FeSO}_{4} \mathrm{OH}$ 
reduce the energy difference between $\mathrm{LiFeSO}_{4} \mathrm{OH}$ and $\mathrm{FeSO}_{4} \mathrm{OH}$, resulting in a lower voltage in accordance with eq 1. We recognize that numerous other interconnected factors contribute to the voltage of a material such as the energy of the transition metal redox couple, the Madelung energy, and inductive effects, but van der Waals effects are also important for this layered hydroxysulfate.

As a comparison, we have also computed the voltage of the tavorite structure of $\mathrm{LiFeSO}_{4} \mathrm{OH}$ using both standard DFT+U and DFT+U+optPBE-vdW. The calculated voltage of $3.40 \mathrm{~V}$ vs $3.20 \mathrm{~V}$ from experiment is not affected by the inclusion of vdW interactions; this result suggests that, as expected, dispersion interactions do not play a major role in the tavorite system. Nevertheless, the tavorite phase provides a useful "reference" system to compare against layered $\mathrm{LiFeSO}_{4} \mathrm{OH}$ and illustrates how significant the effect of vdW interactions is on the voltage of the layered phase.

Finally, we turn our attention to the question of possible proton mobility in these hydroxysulfate systems. Numerous mixed metal oxides and sulfates (e.g., $\mathrm{CsHSO}_{4}$ ) are known to exhibit proton conductivity. ${ }^{66,67}$ It is therefore natural to question how tightly bound the proton is in the hydroxysulfates and whether any proton mobility is possible. The delithiated layered $\mathrm{FeSO}_{4} \mathrm{OH}$ phase is the most likely candidate for proton mobility since the interlayer region is not occupied by $\mathrm{Li}$ ions. However, since full delithiation of this system is not found experimentally we modeled a composition of $\mathrm{Li}_{0.25} \mathrm{FeSO}_{4} \mathrm{OH}$ to test for proton mobility using ab initio molecular dynamics with the vdW functional again included. The results indicate that the $\mathrm{H}$ atoms remain on-site and only exhibit the usual atomic vibrations. By contrast, if the same MD simulation is repeated with the vdW functional not included then proton transfer onto an $\mathrm{SO}_{4}$ unit occurs within a short time scale (Supporting Information, Figure S2), which has not been observed experimentally. This again indicates that $\mathrm{vdW}$ interactions in these calculations are essential in reproducing the observed properties of the material and to the structural integrity of the delithiated phase.

\section{CONCLUSIONS}

This investigation of the layered- $\mathrm{LiFeSO}_{4} \mathrm{OH}$ cathode material has used both atomistic modeling and density functional theory (DFT) techniques to examine the $\mathrm{Li}^{+}$migration pathways and structural van der Waals effects. For comparison, we have also examined the tavorite-structured phase.

Four main features emerge. First, the defect energy results suggest there would be no significant intrinsic concentration of $\mathrm{Fe}$ on $\mathrm{Li}$ sites in these hydroxysulfates at battery operating temperatures, in contrast to the $\mathrm{LiFePO}_{4}$ material. Second, lithium diffusion in layered- $\mathrm{LiFeSO}_{4} \mathrm{OH}$ follows curved pathways in the $b c$-plane with low migration energies $(\sim 0.2 \mathrm{eV})$, suggesting high Li mobility in a 2D network, which is important for good rate performance and capacity retention. Lithium diffusion within tavorite- $\mathrm{LiFeSO}_{4} \mathrm{OH}$ is found to have higher activation energies $(\sim 0.7 \mathrm{eV})$, suggesting much slower $2 \mathrm{D} \mathrm{Li}$ mobility.

Third, DFT calculations show that there are significant interlayer van der Waals (vdW) interactions in the layered phase, which are not fully incorporated in conventional DFT. The reproduction of the experimental structure and voltage of layered $\mathrm{LiFeSO}_{4} \mathrm{OH}$ is only achieved if these dispersion forces are included through an explicit van der Waals functional (DFT $+\mathrm{U}+$ optPBE-vdW). By contrast, the inclusion of van der Waals effects in the tavorite phase does not alter the calculated structure or cell voltage, which are already in good agreement with experiment and indicate a key difference between the two $\mathrm{LiFeSO}_{4} \mathrm{OH}$ structures. Finally, we note that ab initio $\mathrm{MD}$ simulations with the inclusion of vdW effects for the layered hydroxysulfate near to a state of full discharge $\left(\mathrm{Li}_{0.25} \mathrm{FeSO}_{4} \mathrm{OH}\right)$ show no evidence of proton mobility.

In general, this study indicates the importance of including van der Waals effects in DFT calculations on layered-structured materials for lithium-ion batteries, which have not been widely examined in inorganic polyanion-type cathodes.

\section{ASSOCIATED CONTENT}

\section{Supporting Information}

Interlayer binding energy curve for layered $\mathrm{FeSO}_{4} \mathrm{OH}$. Voltages computed with G06 empirical vdW correction. Structural changes during AIMD annealing. This material is available free of charge via the Internet at http://pubs.acs.org.

\section{AUTHOR INFORMATION}

\section{Corresponding Author}

*(M.S.I.) E-mail: m.s.islam@bath.ac.uk.

\section{Author Contributions}

All authors have given approval to the final version of the manuscript.

\section{Notes}

The authors declare no competing financial interest.

\section{ACKNOWLEDGMENTS}

This work was funded by EPSRC Supergen and Programme grants (EP/H019596/1 and EP/K016288/1) and made use of the high-performance computing service HECToR via the HPC Materials Chemistry Consortium (EP/F067496/1).

\section{REFERENCES}

(1) Armand, M.; Tarascon, J. M. Nature 2008, 451, 652.

(2) Goodenough, J. B.; Kim, Y. Chem. Mater. 2010, 22, 587.

(3) Ellis, B. L.; Lee, K. T.; Nazar, L. F. Chem. Mater. 2010, 22, 691.

(4) Palacin, M. R. Chem. Soc. Rev. 2009, 38, 2565.

(5) Padhi, A. K.; Nanjundaswamy, K. S.; Goodenough, J. B. J. Electrochem. Soc. 1997, 144, 1188.

(6) Nyten, A.; Abouimrane, A.; Armand, M.; Gustafsson, T.; Thomas, J. O. Electrochem. Commun. 2005, 7, 156.

(7) Islam, M. S.; Dominko, R.; Masquelier, C.; Sirisopanaporn, C.; Armstrong, A. R.; Bruce, P. G. J. Mater. Chem. 2011, 21, 9811.

(8) Yamada, A.; Iwane, N.; Harada, Y.; Nishimura, S.; Koyama, Y.; Tanaka, I. Adv. Mater. 2010, 22, 3583.

(9) Recham, N.; Chotard, J. N.; Dupont, L.; Delacourt, C.; Walker, W.; Armand, M.; Tarascon, J. M. Nat. Mater. 2010, 9, 68.

(10) Barpanda, P.; Ati, M.; Melot, B. C.; Rousse, G.; Chotard, J.-N.; Doublet, M.-L.; Sougrati, M. T.; Corr, S. A.; Jumas, J.-C.; Tarascon, J.M. Nat. Mater. 2011, 10, 772-779.

(11) Rousse, G.; Tarascon, J.-M. Chem. Mater. 2014, 26, 394.

(12) Ellis, B. L.; Makahnouk, W. R. M.; Makimura, Y.; Toghill, K.; Nazar, L. F. Nat. Mater. 2007, 6, 749.

(13) Nishimura, S.; Nakamura, M.; Natsui, R.; Yamada, A. J. Am. Chem. Soc. 2010, 132, 13596.

(14) Subban, C. V.; Ati, M.; Rousse, G.; Abakumov, A. M.; Van Tendeloo, G.; Janot, R.; Tarascon, J. M. J. Am. Chem. Soc. 2013, 135, 3653.

(15) Reddy, M. A.; Pralong, V.; Caignaert, V.; Varadaraju, U. V.; Raveau, B. Electrochem. Commun. 2009, 11, 1807.

(16) Ati, M.; Sougrati, M. T.; Rousse, G.; Recham, N.; Doublet, M. L.; Jumas, J. C.; Tarascon, J. M. Chem. Mater. 2012, 24, 1472. 
(17) Radha, A. V.; Subban, C. V.; Sun, M. L.; Tarascon, J. M.; Navrotsky, A. J. Mater. Chem. 2014, 2, 6887.

(18) Zhou, F.; Cococcioni, M.; Marianetti, C. A.; Morgan, D.; Ceder, G. Phys. Rev. B 2004, 70, 23.

(19) Zhou, H.; Upreti, S.; Chernova, N. A.; Hautier, G.; Ceder, G.; Whittingham, M. S. Chem. Mater. 2011, 23, 293.

(20) Hautier, G.; Jain, A.; Chen, H. L.; Moore, C.; Ong, S. P.; Ceder, G. J. Mater. Chem. 2011, 21, 17147.

(21) Armstrong, A. R.; Lyness, C.; Panchmatia, P. M.; Islam, M. S.; Bruce, P. G. Nat. Mater. 2011, 10, 223.

(22) Eames, C.; Armstrong, A. R.; Bruce, P. G.; Islam, M. S. Chem. Mater. 2012, 24, 2155.

(23) Islam, M. S.; Driscoll, D. J.; Fisher, C. A. J.; Slater, P. R. Chem. Mater. 2005, 17, 5085.

(24) Fisher, C. A. J.; Prieto, V. M. H.; Islam, M. S. Chem. Mater. 2008, 20, 5907.

(25) Gardiner, G. R.; Islam, M. S. Chem. Mater. 2010, 22, 1242.

(26) Kuganathan, N.; Islam, M. S. Chem. Mater. 2009, 21, 5196.

(27) Armstrong, A. R.; Kuganathan, N.; Islam, M. S.; Bruce, P. G. J. Am. Chem. Soc. 2011, 133, 13031.

(28) Tripathi, R.; Gardiner, G. R.; Islam, M. S.; Nazar, L. F. Chem. Mater. 2011, 23, 2278.

(29) Yahia, M. B.; Lemoigno, F.; Rousse, G.; Boucher, F.; Tarascon, J.-M.; Doublet, M.-L. Energy. Environ. Sci. 2012, 5, 9584.

(30) Clark, J. M.; Nishimura, S.; Yamada, A.; Islam, M. S. Angew. Chem., Int. Ed. 2012, 51, 13149.

(31) Catlow, C. R. A. Computer Modelling in Inorganic Crystallography; Academic Press: San Diego, CA, 1997.

(32) Islam, M. S.; Fisher, C. A. J. Chem. Soc. Rev. 2014, 43, 185.

(33) Allan, N. L.; Rohl, A. L.; Gay, D. H.; Catlow, C. R. A.; Davey, R. J.; Mackrodt, W. C. Faraday Discuss. 1993, 95, 273.

(34) Redfern, S. E.; Parker, S. C. J. Chem. Soc., Faraday Trans. 1998, 94, 1947.

(35) Sastre, G.; Gale, J. D. Chem. Mater. 2005, 17, 730.

(36) Gomez-Hortiguela, L.; Cora, F.; Catlow, C. R. A.; PerezPariente, J. J. Am. Chem. Soc. 2004, 126, 12097.

(37) Dick, B. G.; Overhauser, A. W. Phys. Rev. 1958, 112, 90.

(38) Panchmatia, P. M.; Orera, A.; Kendrick, E.; Hanna, J. V.; Smith, M. E.; Slater, P. R.; Islam, M. S. J. Mater. Chem. 2010, 20, 2766.

(39) Stokes, S. J.; Islam, M. S. J. Mater. Chem. 2010, 20, 6258.

(40) Panchmatia, P. M.; Orera, A.; Rees, G. J.; Smith, M. E.; Hanna, J.

V.; Slater, P. R; Islam, M. S. Angew. Chem., Int. Ed. 2011, 50, 9328.

(41) Henson, N. J.; Hay, P. J.; Redondo, A. J. Phys. Chem. A 2000, 104, 2423.

(42) Gale, J. D.; Rohl, A. L. Mol. Simul. 2003, 29, 291.

(43) Kresse, G.; Furthmuller, J. Phys. Rev. B 1996, 54, 11169.

(44) Blochl, P. E. Phys. Rev. B 1994, 50, 17953.

(45) Kresse, G.; Joubert, D. Phys. Rev. B 1999, 59, 1758.

(46) Perdew, J. P.; Burke, K.; Ernzerhof, M. Phys. Rev. Lett. 1996, 77, 3865.

(47) Reynaud, M.; Rousse, G.; Chotard, J.-N.; Rodriguez-Carvajal, J.; Tarascon, J.-M. Inorg. Chem. 2013, 52, 10456.

(48) Melot, B. C.; Rousse, G.; Chotard, J.-N.; Ati, M.; RodriguezCarvajal, J.; Kemei, M. C.; Tarascon, J.-M. Chem. Mater. 2011, 23, 2922.

(49) Melot, B. C.; Rousse, G.; Chotard, J.-N.; Kemei, M. C.; Rodriguez-Carvajal, J.; Tarascon, J.-M. Phys. Rev. B 2012, 85, 094415.

(50) Zhou, F.; Cococcioni, M.; Kang, K.; Ceder, G. Electrochem. Commun. 2004, 6, 1144.

(51) Arroyo-de Dompablo, M. E.; Armand, M.; Tarascon, J. M.; Amador, U. Electrochem. Commun. 2006, 8, 1292.

(52) Ceder, G.; Aydinol, M. K.; Kohan, A. F. Comput. Mater. Sci. 1997, 8, 161.

(53) Arrouvel, C.; Parker, S. C.; Islam, M. S. Chem. Mater. 2009, 21, 4778.

(54) Maier, J.; Amin, R. J. Electrochem. Soc. 2008, 155, A339.

(55) Chen, J. J.; Vacchio, M. J.; Wang, S. J.; Chernova, N.; Zavalij, P. Y.; Whittingham, M. S. Solid State Ionics 2008, 178, 1676.
(56) Nishimura, S.; Kobayashi, G.; Ohoyama, K.; Kanno, R.; Yashima, M.; Yamada, A. Nat. Mater. 2008, 7, 707.

(57) Rydberg, H.; Dion, M.; Jacobson, N.; Schroder, E.; Hyldgaard, P.; Simak, S. I.; Langreth, D. C.; Lundqvist, B. I. Phys. Rev. Lett. 2003, 91, 126402.

(58) Bucko, T.; Hafner, J.; Lebegue, S.; Angyan, J. G. J. Phys. Chem. A 2010, 114, 11814.

(59) Marom, N.; Bernstein, J.; Garel, J.; Tkatchenko, A.; Joselevich, E.; Kronik, L.; Hod, O. Phys. Rev. Lett. 2010, 105, 046801.

(60) Grimme, S. J. Comput. Chem. 2006, 27, 1787.

(61) Klimes, J.; Bowler, D. R.; Michaelides, A. Phys. Rev. B 2011, 83, 195131.

(62) Persson, K.; Hinuma, Y.; Meng, Y. S.; Van der Ven, A.; Ceder, G. Phys. Rev. B 2010, 82, 125416.

(63) Wang, Z.; Selbach, S. M.; Grande, T. RSC Adv. 2014, 4, 4069.

(64) Frayret, C.; Ekaterina, I.; Izgorodina, E.; MacFarlane, D. R.; Villesuzanne, A.; Barrès, A.-L.; Politano, O.; Rebeixd, D.; Poizota, P. Phys. Chem. Chem. Phys. 2012, 14, 11398.

(65) Ramos-Sanchez, G.; Callejas-Tovar, A.; Scanlon, L. G.; Balbuena, P. B. Phys. Chem. Chem. Phys. 2014, 16, 743-52.

(66) Kreuer, K. D. Annu. Rev. Mater. Res. 2003, 33, 333.

(67) Malavasi, L.; Fisher, C. A. J.; Islam, M. S. Chem. Soc. Rev. 2010, $39,4370$. 